\title{
Electrochemical Behavior of Chalcone at a Glassy Carbon Electrode and Its Analytical Applications
}

\author{
Keerti M. Naik, Sharanappa T. Nandibewoor* \\ P. G. Department of Studies in Chemistry, Karnatak University, Dharwad, India \\ Email: "stnandibewoor@yahoo.com
}

Received May 5, 2012; revised June 8, 2012; accepted June 18, 2012

\begin{abstract}
A simple and rapid method was developed using cyclic, differential pulse and square wave voltammetric techniques for the determination of trace-level chalcone at a glassy carbon electrode. Chalcone could produce two anodic peaks at about $0.514 \mathrm{~V}$ and $1.478 \mathrm{~V}$ and a cathodic peak at about $-0.689 \mathrm{~V}$. The differential pulse voltammerty presents a good linear response as compared to square wave voltammetry in the range of $0.2-10 \mu \mathrm{M}$ with a detection limit of $0.18 \mu \mathrm{M}$. The proposed method was used successfully for its quantitative determination in spiked human plasma and urine as real samples.
\end{abstract}

Keywords: Chalcone; Voltammetry; Glassy Carbon Electrode; Electrochemical Determination; Oxidation

\section{Introduction}

Chalcone (1,3-Diphenyl-2-propen-1-one) (Scheme 1) is an aromatic ketone that forms the central core for a variety of important biological compounds, which are known collectively as chalconoids. They show antibacterial, antifungal, antitumor and anti-inflammatory properties [1]. Some chalcones demonstrated the ability to block voltage-dependent potassium channels [2]. They are also intermediates in the biosynthesis of flavonoids, which are substances widespread in plants and with an array of biological activities. Chalcones are also intermediates in the Auwers synthesis of flavones. Due to ineffective drugs, cancer is the second most leading cause of death after heart attack. Therefore, the researchers have accelerated their efforts for the generation of new anticancer drugs with high therapeutic index. In this connection, a clinically effective antitumor derivative of chalcone (calicheamicin) has stimulated the investigators to concentrate their studies on chalcones and related compounds [3].

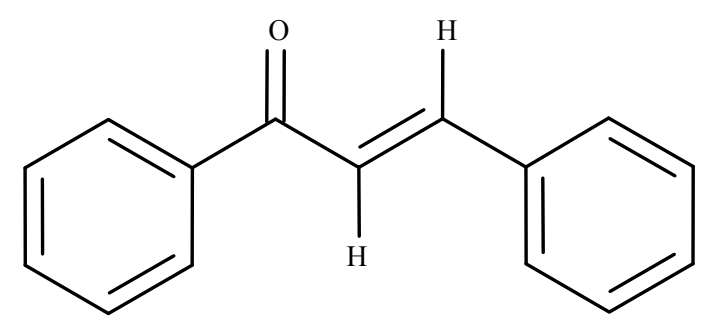

Scheme 1. Chemical structure of chalcone.

*Corresponding author.
Electrochemical methods have proved to be very sensitive for the determination of organic molecules, including drugs and related molecules in pharmaceutical dosage forms and biological fluids [4-8]. The advance in experimental electrochemical techniques in the field of analysis of drugs is due to their simplicity, low cost and relatively short analysis time when compared with the other techniques. The use of carbon based electrodes, especially glassy carbon electrode, for electroanalytical measurements has increased in recent years because of their applicability to the determination of substances that undergo oxidation reactions, a matter of great importance in the field of clinical and pharmaceutical analysis. Redox properties of drugs can give insights into its metabolic fate or their in vivo redox processes or pharmaceutical activity $[9,10]$.

A review of the literature reveals that only the oxidation of chalcone by trichloroisocyanuric acid in HOAc$\mathrm{HClO}_{4}$ medium [11] and the interaction of substituted chalcone with DNA [12] have been reported. However, no methods for determination of chalcone have been reported so far. There is also no report on the electro-oxidation of chalcone with any of the electrodes. In view of the pharmaceutical importance of chalcone and the lack of literature on its voltammetric determination, the electro oxidation of chalcone necessitates a method to be developed. The aim of the present study is to establish the suitable experimental conditions, to investigate the oxidation mechanism of chalcone and determine chalcone in spiked human plasma and urine samples using cyclic, square wave and differential pulse voltammetric techniques. 


\section{Experimental}

\subsection{Materials and Reagents}

Pure chalcone in powdered form was obtained from Sigma Aldrich and used without further purification. A stock solution of chalcone $\left(1 \times 10^{-3} \mathrm{M}\right)$ was prepared by direct dissolution in methanol, since it is insoluble in water. The phosphate buffers from $\mathrm{pH} 3-11.2$ were prepared in double distilled water as described by Christian and Purdy [13]. All other reagents used were of analytical or reagent grade and their solutions were prepared with double distilled water.

\subsection{Instrumentation}

Electrochemical measurements were carried out on a CHI $630 \mathrm{D}$ electrochemical analyzer (CH Instruments Inc., USA). The voltammetric measurements were carried out in a $10 \mathrm{ml}$ single compartment three-electrode glass cell with $\mathrm{Ag} / \mathrm{AgCl}$ as a reference electrode, a platinum wire as counter electrode and a $3 \mathrm{~mm}$ diameter glassy carbon electrode (GCE) as the working electrode. All the potentials are given against the $\mathrm{Ag} / \mathrm{AgCl}(3 \mathrm{M} \mathrm{KCl})$. The $\mathrm{pH}$ measurements were performed with Elico LI120 pH meter (Elico Ltd., India). All experiments were carried out at an ambient temperature of $25^{\circ} \mathrm{C} \pm 0.1{ }^{\circ} \mathrm{C}$.

The area of the electrode was calculated using $1.0 \mathrm{mM}$ $\mathrm{K}_{3} \mathrm{Fe}(\mathrm{CN})_{6}$ as a probe at different scan rates. For a reversible process, the Randles-Sevcik formula has been used [14].

$$
\mathrm{i}_{\mathrm{pa}}=\left(2.69 \times 10^{5}\right) \mathrm{n}^{3 / 2} \mathrm{AD}_{0}^{1 / 2} \mathrm{C}_{0} \mathrm{v}^{1 / 2}
$$

where $i_{p a}$ refers to the anodic peak current, $n$ is the number of electrons transferred, $\mathrm{A}$ is the surface area of the electrode, $\mathrm{D}_{0}$ is diffusion coefficient, $v$ is the scan rate and $\mathrm{C}_{0}$ is the concentration of $\mathrm{K}_{3} \mathrm{Fe}(\mathrm{CN})_{6}$. For $1.0 \mathrm{mM}$ $\mathrm{K}_{3} \mathrm{Fe}(\mathrm{CN})_{6}$ in $0.1 \mathrm{M} \mathrm{KCl}$ electrolyte, $\mathrm{n}=1 . \mathrm{D}_{0}=7.6 \times$ $10^{-6} \mathrm{~cm}^{2} \cdot \mathrm{s}^{-1}$ [14], then from the slope of the plot of $i_{\mathrm{pa}}$ versus $v^{1 / 2}$, relation, the surface area of electrode was calculated. In our experiment, the slope obtained was $2.46 \times$ $10^{-6}$ and the surface area of glassy carbon electrode was calculated to be $0.033 \mathrm{~cm}^{2}$.

\subsection{Analytical Procedure}

The GCE was carefully polished using 0.3 micron $\mathrm{Al}_{2} \mathrm{O}_{3}$ slurry on a polishing cloth before each experiment. After polishing, the electrode was rinsed thoroughly with water. After this mechanical treatment, the GCE was placed in buffer solution and various voltammogramms were recorded until a steady state baseline voltammogram was obtained.

The GCE was first activated in phosphate buffer $(\mathrm{pH}$ 3.0) by cyclic voltammetric sweeps between -2 to and $3.0 \mathrm{~V}$ until stable cyclic voltammograms were obtained. Then electrodes were transferred into another $10 \mathrm{ml}$ of phosphate buffer ( $\mathrm{pH}$ 3.0) containing proper amount of chalcone. After accumulating for $10 \mathrm{~s}$ at open circuit under stirring and following quiet for $10 \mathrm{~s}$, potential scan was initiated and cyclic voltammograms were recorded between -2 and $3.0 \mathrm{~V}$, with a scan rate of $50 \mathrm{~m} \cdot \mathrm{Vs}^{-1}$.

\subsection{Plasma sample Preparation}

Human blood samples were collected in dry and evacuated tubes (which contained saline and sodium citrate solution) from same healthy volunteer. The samples were handled at room temperature and were centrifuged for 10 $\min$ at $1500 \mathrm{rpm}$ for the separation of plasma within 1 hour of collection. The samples were then transferred to polypropylene tubes and stored at $20^{\circ} \mathrm{C}$ until analysis. The plasma samples, $0.2 \mathrm{~mL}$, were deproteinized with 2 $\mathrm{mL}$ of methanol, vortexed for 15 minutes centrifuged at 6000 RPM for $15 \mathrm{~min}$, and supernatants were collected. The supernatants were spiked with an appropriate volume of chalcone. Appropriate volumes of this solution were added to phosphate buffer $\mathrm{pH} 3.0$ as supporting electrolyte and the voltammograms were then recorded.

\section{Results and Discussion}

\subsection{Cyclic Voltammetric Behavior of Chalcone}

In order to understand the electrochemical process occurring at the glassy carbon electrode, cyclic voltammetry was carried out. Chalcone was oxidized on glassy carbon electrode between $\mathrm{pH} 3.0$ and 11.2 of phosphate buffer, producing two well-defined oxidation peaks and one reduction peak. The cyclic voltammograms of chalcone at pH 3.0 in phosphate buffer was as shown in Figure 1. The blank solution without chalcone was shown by curve (b) and anodic peaks corresponding to chalcone oxidation appeared at $0.514 \mathrm{~V}$ (peak A) and $1.478 \mathrm{~V}$ (peak B) and a cathodic peak at $-0.689 \mathrm{~V}$ (peak C) as shown in

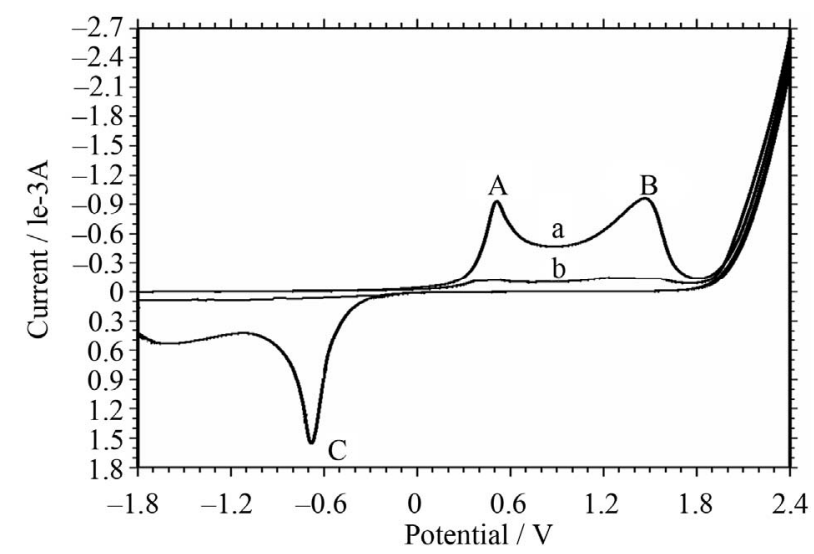

Figure 1. Cyclic voltammogram obtained for $10 \mu \mathrm{M}$ chalcone on glassy carbon electrode in $\mathrm{pH}$ 3.0 $0.2 \mathrm{M}$ buffer: (a) chalcone and (b) blank run without chalcone at $v=50 \mathrm{~m} \cdot \mathrm{Vs}^{-1}$ : accumulation time: $10 \mathrm{~s}$ (at open circuit). 
curve (a). The peak current for the first wave was found to increase with increase in concentration of chalcone. The plot $i_{p}$ vs. concentration was linear in the range 0.2 to $10.0 \mu \mathrm{M}$ and deviates from linearity above $10 \mu \mathrm{M}$. This is due to the adsorption of chalcone or chalcone oxidation product at higher concentration.

It is shown that the reduction peak was observed in the reverse scan, suggesting that the electrochemical reaction was a quasi-reversible process [15]. Nevertheless, it was found that the oxidation peak current of chalcone showed a remarkable decrease during the successive cyclic voltammetric sweeps. After every sweep, the peak current decreased greatly and finally remained unchanged. This phenomenon may be attributed to the consumption of adsorbed chalcone on the electrode surface or due to the fact that the adsorption of oxidative product occurs at the electrode surface. Therefore, the voltammograms corresponding to the first cycle and peak A were generally recorded, since peak A was more intense than B.

\subsection{Influence of Accumulation Potential and Time}

It was important to fix the accumulation potential and time when adsorption studies were undertaken. Both conditions could affect the amount of adsorption of chalcone at the electrode. Bearing this in mind, the effect of accumulation potential and time on peak current response was studied by $\mathrm{CV}$. The concentration of chalcone used was $10 \mu \mathrm{M}$.

When accumulation potential was varied from +0.4 to $-0.4 \mathrm{~V}$, the peak current changed a little. Hence, accumulation at open circuit was adopted. The peak current increased very rapidly with increasing accumulation time, which induced rapid adsorption of oxidative product on the surface of the GCE. The peak current reached the maximum at $10 \mathrm{~s}$ and their after being decreased which indicates the saturation accumulation.

\subsection{Influence of $\mathrm{pH}$}

The electrochemical oxidation of chalcone was studied with different supporting electrolytes such as Britton-Robinson buffer and phosphate buffer. Within the range of $\mathrm{pH} 3.0$ 11.2 , the phosphate buffer gave the good results as compared to other supporting electrolytes. Hence phosphate buffers were taken as a supporting electrolyte. With increasing the $\mathrm{pH}$ of the buffer solution, the peak potential shifted to less positive values as shown in Figure 2 .

The plot of $E_{p}$ versus $p H$ (Figure 3(a)) shows that the peak potential is $\mathrm{pH}$ dependent. The variation of peak current with $\mathrm{pH}$ is as shown in Figure 3(b). The peak current decreased from $\mathrm{pH} 3$ - 11.2. The voltammetric response was markedly dependent on $\mathrm{pH}$. From the experimental results, (Figure 2) it is observed that highest peak current and better shape of the voltammogram was ob- served at $\mathrm{pH} 3.0$, suggesting this $\mathrm{pH}$ is optimal $\mathrm{pH}$ value. From the plot of current versus $\mathrm{pH}$ (Figure 3(b)) it is evident that current goes on decreasing with increase in $\mathrm{pH}$. Hence $\mathrm{pH}$ variation is restricted to 11.2.

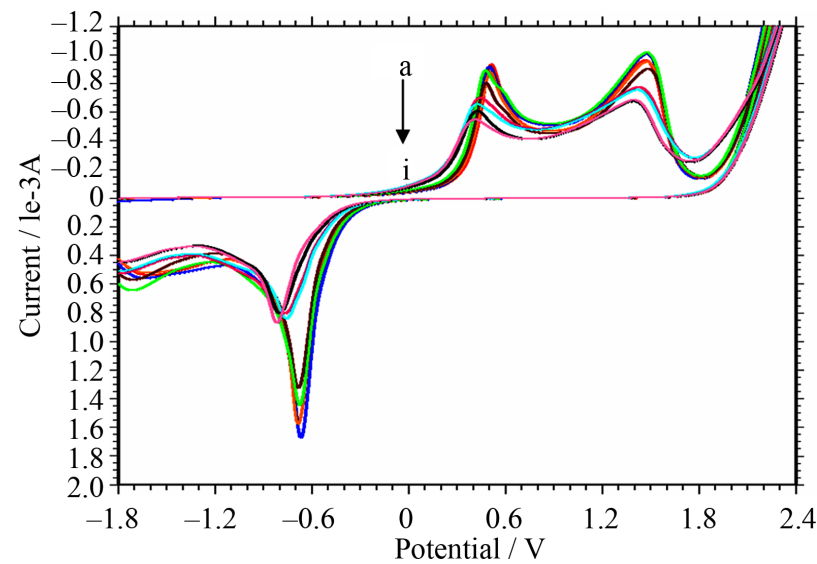

Figure 2. Influence of $\mathrm{pH}$ on the shape of the peaks in phosphate buffer solution at (a) $\mathrm{pH}$ 3.0; (b) $\mathrm{pH} \mathrm{4.2;} \mathrm{(c)} \mathrm{pH} \mathrm{5.0;}$ (d) $\mathrm{pH} 6.0$; (e) $\mathrm{pH} 7.0$; (f) $\mathrm{pH} 8.0$; (g) $\mathrm{pH} 9.2$; (h) $\mathrm{pH} 10.4$ and (i) pH 11.2. Other conditions are as in Figure 1.

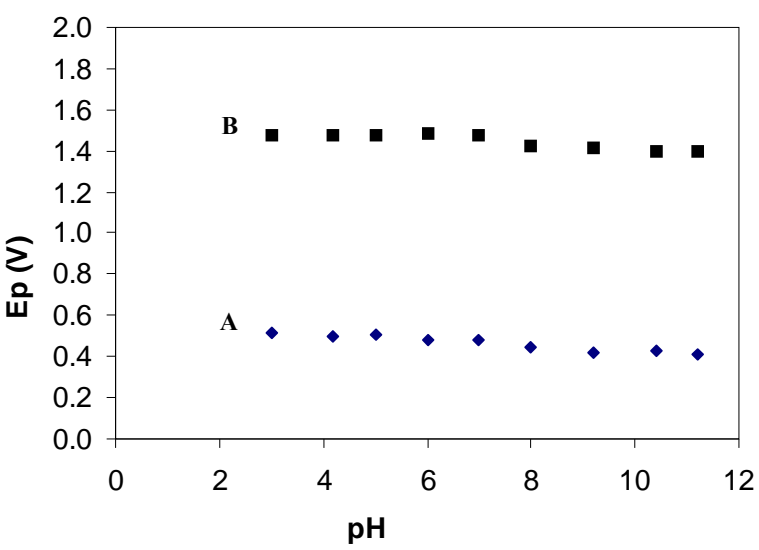

(a)

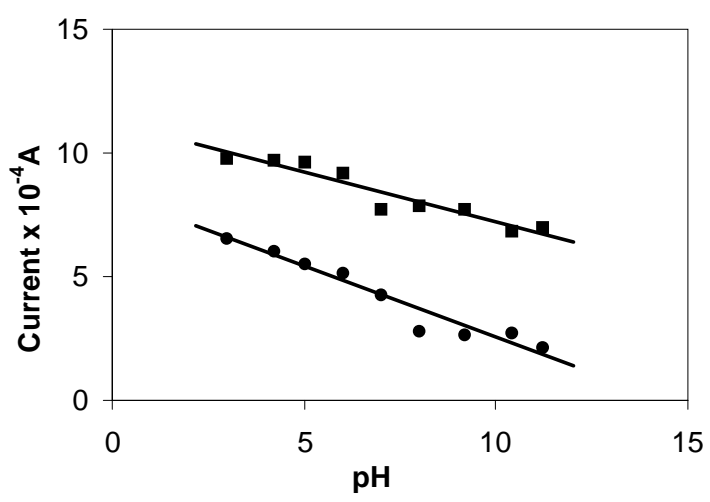

(b)

Figure 3. (a) Influence of $\mathrm{pH}$ on the peak potential of chalcone for peaks $A$ and $B$. Other conditions are as in Figure 1; (b) Variation of peak currents of peaks $\mathrm{A}$ and $\mathrm{B}$ with $\mathrm{pH}$. Other conditions are as in Figure 1. 


\subsection{Influence of Scan Rate}

Useful information involving electrochemical mechanism usually can be acquired from the relationship between peak current and scan rate. Therefore, the electrochemical behavior of chalcone at different scan rates from 50 to 300 $\mathrm{m} \cdot \mathrm{Vs}^{-1}$ (Figure 4) was also studied. From this we observed that increasing the scan rate, the peak potential of $\mathrm{A}$ is shifted to more positive values. Simultaneously, the width at half-height of peak A increases. It is suggested that this corresponds to the oxidation of chalcone dimers formed at the GCE surface. The formation of such kind of dimers is well documented in the literature $[16,17]$, but they can only be observed when high scan rates are used probably because they have short life time.

At the same time, the cathodic peak $\mathrm{C}$ is displaced to more negative values whereas its current increases with the scan rate. Nevertheless, the fact that peak current of $\mathrm{C}$ is always smaller than the peak current of A suggests that the oxidation product of chalcone is very unstable and undergoes hydrolysis in the solution [18].

There is a good linear relationship between peak current and scan rate. The equations are

$$
\mathrm{I}_{\mathrm{p}}\left(10^{-4} \mathrm{~A}\right)=4.6745 v\left(\mathrm{Vs}^{-1}\right)-0.7531, \mathrm{r}=0.9821
$$

and $I_{p}\left(10^{-4} A\right)=5.7583 v\left(\mathrm{Vs}^{-1}\right)-0.8515, \mathrm{r}=0.9828$

for peaks A and B, respectively as shown in Figure 5(a). In addition, there was a linear relation between $\log \mathrm{I}_{\mathrm{p}}$ and $\log v$, corresponding to the following equation:

$$
\log \mathrm{I}_{\mathrm{p}}\left(10^{-4} \mathrm{~A}\right)=0.4881 \log v\left(\mathrm{Vs}^{-1}\right)+0.5813, \mathrm{r}=0.9917
$$

and

$$
\log \mathrm{I}_{\mathrm{p}}\left(10^{-4} \mathrm{~A}\right)=0.516 \log v\left(\mathrm{Vs}^{-1}\right)+0.6706, \mathrm{r}=0.9842,
$$

for peaks A and B, respectively (Figure 5(b)). The slope of 0.4881 and 0.516 is close to the theoretically expected value of 0.5 for a diffusion controlled process [19].

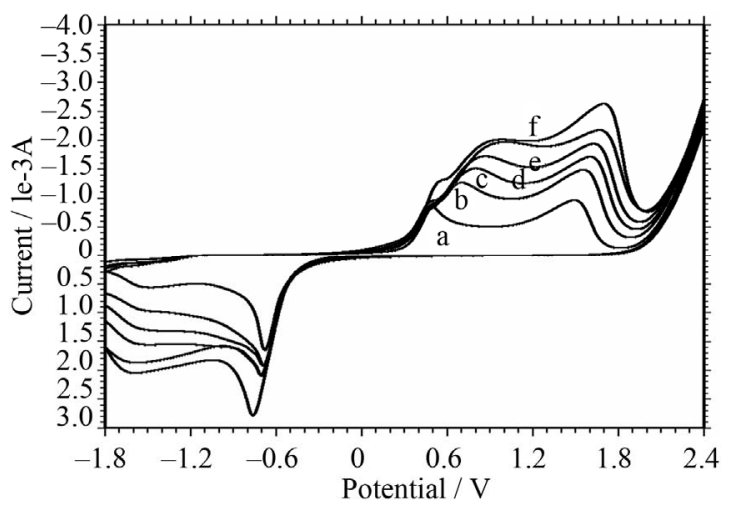

Figure 4. Cyclic voltammograms of $10 \mu \mathrm{M}$ chalcone on GCE with different scan rates, (a) - (f) were 50, 100, 150, 200, 250 and $300 \mathrm{~m} \cdot \mathrm{Vs}^{-1}$, respectively. Other conditions are as in Figure 1.

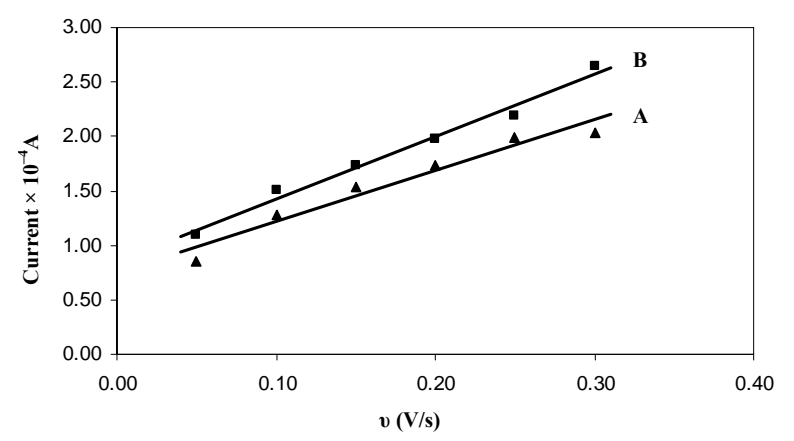

(a)

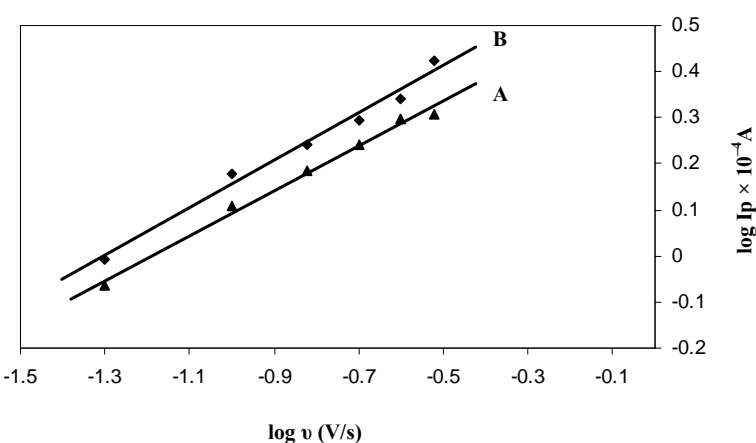

(b)

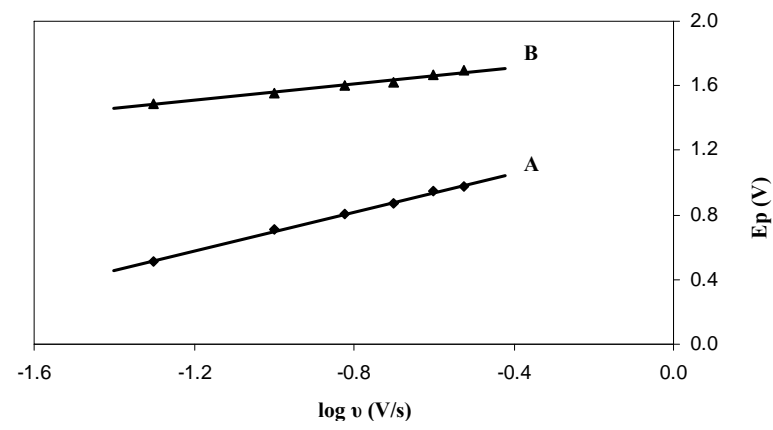

(c)

Figure 5. (a) Dependence of the oxidation peak current of peaks $A$ and $B$ on the scan rate; (b) Dependence of the logarithm of peak current on logarithm of scan rate for peaks $A$ and B; (c) Relationship between peak potential and logarithm of scan rate for the peaks $A$ and $B$.

The peak potential shifted to more positive values with increasing the scan rates. The linear relationship between peak potential and logarithm of scan rate can be expressed as

and

$$
\begin{aligned}
& \mathrm{E}_{\mathrm{p}}(\mathrm{V})=0.5993 \log v\left(\mathrm{Vs}^{-1}\right)+1.2974 \\
& \mathrm{E}_{\mathrm{p}}(\mathrm{V})=0.2591 \log v\left(\mathrm{Vs}^{-1}\right)+1.8196
\end{aligned}
$$

for the peaks A and B, respectively (Figure 5(c)).

According to the quasi reversible electrode process, $\mathrm{I}_{\mathrm{p}}$ is defined by the following equation [20]:

$$
\mathrm{I}_{\mathrm{p}}=2.69 \times 10^{5} \times \mathrm{n}\left(\alpha \mathrm{n}_{\mathrm{a}}\right)^{1 / 2} \times \mathrm{A} \times\left(\mathrm{D}_{\mathrm{o}}\right)^{1 / 2} \times(v)^{1 / 2} \times \mathrm{C}_{\mathrm{o}}
$$

where $\alpha$ (alpha) is the transfer coefficient, $\mathrm{n}_{\mathrm{a}}$ the number 
of electrons transferred, $v(\mathrm{nu})$ the scan rate, $\mathrm{A}$ is the electrode area, $D_{0}$ is the diffusion coefficient and $C_{o}$ is the concentration of electro active species $(10 \mu \mathrm{M})$. Thus the value of $D_{o}$ is taken from the slope of $I_{p}$ versus $v^{1 / 2}$. In this system, for peak $A$, the slope was $3.7 \times 10^{-3}$. The $\alpha \mathrm{n}_{\mathrm{a}}$ was calculated according to the following equation:

$$
\alpha \mathrm{n}_{\mathrm{a}}=\frac{47.7}{\mathrm{E}_{\mathrm{p}}-\mathrm{E}_{\mathrm{p} / 2}} \mathrm{mV}
$$

where $E_{p / 2}$ is the potential where the current is at half the peak value. Further, the number of electron (n) transferred in the electro oxidation of chalcone was calculated to be $2.13 \approx 2.0$.

\subsection{Mechanism}

In the proposed method the chalcone undergoes oxidation with two electrons and the possible mechanisms are as shown in Scheme 2 for peaks A, B and C respectively which are proposed based on the earlier literature [12]. Based on the kinetic data, the proposed mechanism of oxidation of chalcone by trichloroisocynuric acid [TClCA] in $\mathrm{HOAc}-\mathrm{HClO}_{4}$ medium [11] is different. Hence the oxidative pathways of electrochemical and chemical processes are different.
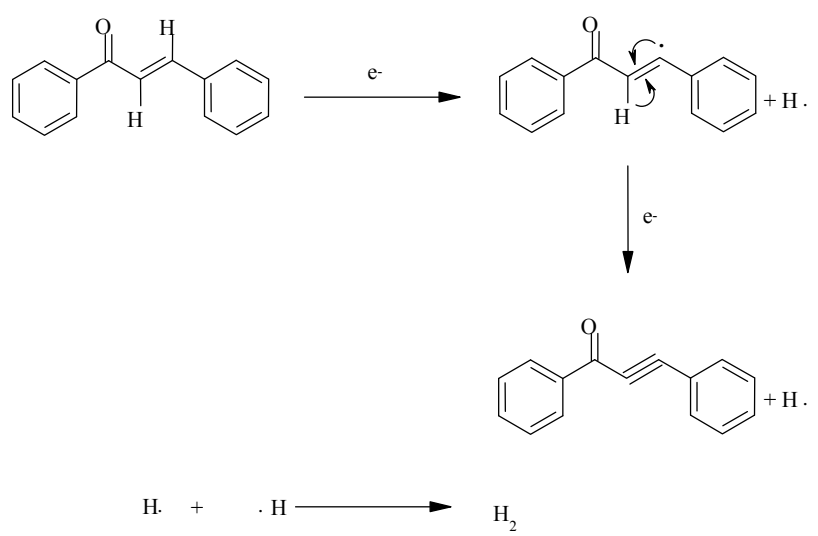

(a)

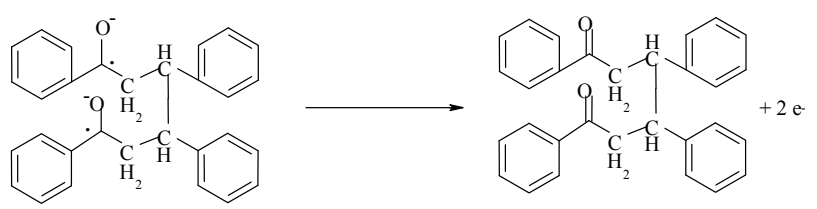

(b)

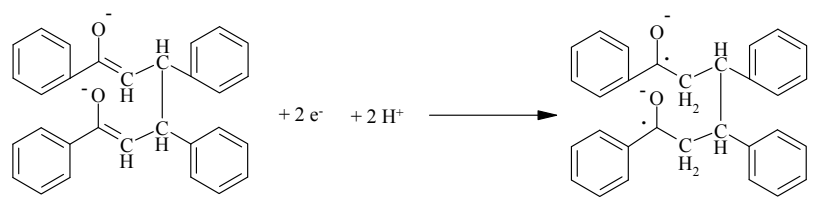

(c)

Scheme 2. Proposed mechanisms of electrooxidation of chalcone for peaks (a), (b) and (c).

\subsection{Calibration Curve}

In order to develop a voltammetric method for determining the drug, we selected the differential pulse (DPV) and square wave voltammetric (SWV) mode, because the peaks are sharper and better defined at lower concentration of chalcone, than those obtained by cyclic voltammetry, with low background current, resulting in improved resolution. According to the obtained results, it was possible to apply these techniques to the quantitative analysis of chalcone. The phosphate buffer solution of $\mathrm{pH} 3.0$ was selected as the supporting electrolyte for the quantification of chalcone as it gave maximum peak current at $\mathrm{pH}$ 3.0. The peak at about $0.275 \mathrm{~V}$ in DPV and $0.26 \mathrm{~V}$ in SWV was considered for the analysis. Differential pulse voltammograms and square wave voltammograms obtained with increasing amount of chalcone showed that the peak current increased linearly with increasing concentration, as shown in Figures 6(a) and (b).

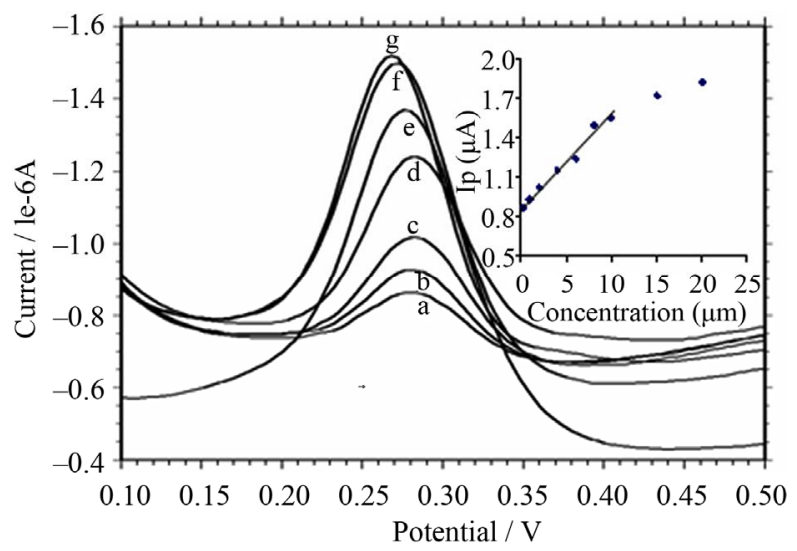

(a)

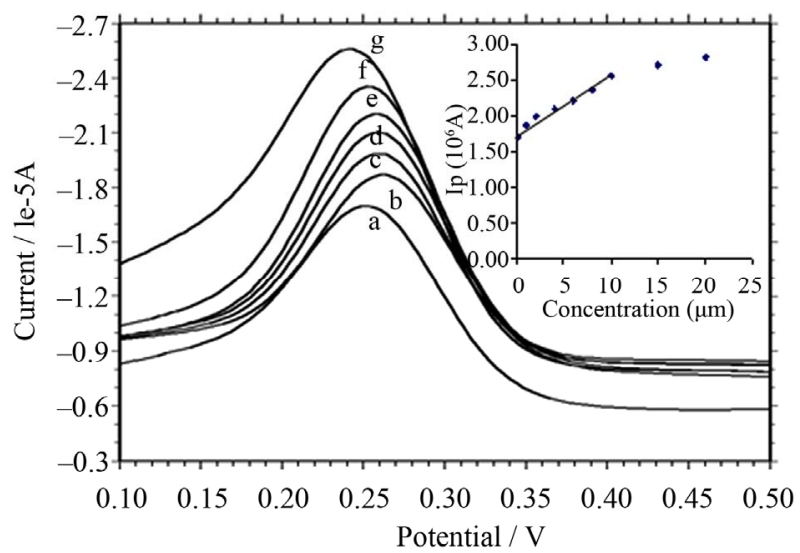

(b)

Figure 6. (a) Differential-pulse voltammograms of GCE in chalcone solution at different concentraions: a: 0.2, b: 1 , c: 2, d: 4, e: $6, f: 8$ and g: $10 \mu M$. Inset plot of the peak current against concentration of chalcone; (b) Square wave voltammograms of GCE in chalcone solution at different concentrations: a: 0.2, b: 1, c: 2 , d: 4 , e: $6, \mathrm{f}: 8$ and g: $10 \mu \mathrm{M}$. Inset plot of the peak current against concentration of chalcone. 
Using the optimum conditions described above, linear calibration curves were obtained for chalcone in the range of 0.2 to $10.0 \mu \mathrm{M}$. The linear equation was

$$
\mathrm{I}_{\mathrm{p}}(\mu \mathrm{A})=72100 \mathrm{C}+0.8606(\mathrm{r}=0.9832, \mathrm{C} \text { is in } \mu \mathrm{M})
$$

and

$$
I_{p}\left(10^{5} A\right)=78200 C+1.7644\left(r=0.9726, C \text { is in } 10^{5} M\right)
$$

for DPV and SWV respectively. The DPV presents a good linear response as compared to SWV in view of a less intercept of linear plot of $I_{p}$ versus concentrations. Deviation from linearity was observed for more concentrated solutions, due to the adsorption of oxidation product on the electrode surface. It was also observed that the peak potential $\left(\mathrm{E}_{\mathrm{p}}\right)$ and half peak potential $\left(\mathrm{E}_{\mathrm{p} / 2}\right)$ were shifted towards more positive value suggesting that product undergoes adsorption at the surface of GCE. Related statistical data of the calibration curves were obtained from five different calibration curves. The limit of detection (LOD) and quantification (LOQ) were $0.18 \mu \mathrm{M}$ and $0.6 \mu \mathrm{M}$, respectively. The LOD and LOQ were calculated using the following equations:

$$
\mathrm{LOD}=3 s / m, \quad \mathrm{LOQ}=10 \mathrm{~s} / \mathrm{m}
$$

where $s$ is the standard deviation of the peak currents of the blank (five runs) and $m$ is the slope of the calibration curve.

\subsection{Stability and Reproducibility}

In order to study the stability and reproducibility of the electrode, a $10 \mu \mathrm{M}$ chalcone solution were measured within the same electrode (renewed every time) for every several hours within day, the RSD of the peak current was $2.88 \%$ (number of measurements $=5$ ). As to the between day reproducibility, it was similar to that of within a day if the temperature was kept almost unchanged which could be attributed to the excellent stability and reproducibility of GCE.

\subsection{Effect of Surfactant}

Surfactants even in trace quantities can exert a strong effect on the electrode process. Adsorption of such substances at the electrode may inhibit the electrolytic process, bring about the irregularity in the voltammograms, and shift in the wave to more negative potentials $[21,22]$.

Surface-active substances have the common tendency of accumulation at interfaces. The lack of affinity between the hydrophobic portion of the surfactant and water leads to a repulsion of these substances from the water phase as a consequence of reduction of the microscopic chalcone water interface. Experimental results showed that the addition of cationic surfactant, cetyltrimethylammonium bromide, as anionic surfactant, sodiumdodecyl sul- fate and the non-ionic surfactant, Triton X-100 have no much influence on the peak current and peak potential.

\subsection{Effect of Interferents}

For the analytical applications of the proposed method, the effect of potential interferents that are likely to be in biological samples were evaluated under the optimum experimental conditions. Differential-pulse voltammetric experiments were carried out for $1.0 \mu \mathrm{M}$ chalcone in the presence of $1.0 \mathrm{mM}$ of each of the interferents. The experimental results (Table 1) showed that thousand-fold excess of glucose, starch, sucrose, dextrose, gum acacia, citric acid, tartaric acid and oxalic acid did not interfere with the voltammetric signal of chalcone. Therefore, the proposed method can be used as a selective method.

\subsection{Detection of Chalcone in Spiked Human Plasma Samples}

The developed differential-pulse voltammetric method for the chalcone determination was applied to spiked human plasma samples. The recoveries from human plasma were measured by spiking drug free plasma with known amounts of chalcone. The plasma samples were prepared as described in experimental section. A quantitative analysis can be carried out by adding the standard solution of chalcone into the detect system of plasma sample. The calibration graph was used for the determination of spiked chalcone in plasma samples. The results of four plasma samples obtained are listed in Table 2. The recovery determined was in the range from $98.0 \%$ to $103.0 \%$ and the RSD was $2.05 \%$.

Table 1. Influence of potential interferents on the voltammetric response of $1.0 \mu \mathrm{M}$ chalcone.

\begin{tabular}{ccc}
\hline Interferent & Concentration $(\mathrm{mM})$ & Signal change $(\%)$ \\
\hline Glucose & 1.0 & -1.6 \\
Starch & 1.0 & -1.2 \\
Sucrose & 1.0 & -1.6 \\
Dextrose & 1.0 & -1.6 \\
Citric acid & 1.0 & -1.2 \\
Tartaric acid & 1.0 & -1.6 \\
Oxalic acid & 1.0 & -1.2 \\
Gum acacia & 1.0 & -1.6 \\
\hline
\end{tabular}

Table 2. Determination of chalcone in spiked human plasma samples.

\begin{tabular}{ccccc}
\hline $\begin{array}{c}\text { Human } \\
\text { plasma }\end{array}$ & Spiked $(\mu \mathrm{M})$ & $\begin{array}{c}\text { Detection }^{(\mathrm{a})} \\
(\mu \mathrm{M})\end{array}$ & Recovery $(\%)$ & $\begin{array}{c}\text { SD } \pm \text { RSD } \\
(\%)\end{array}$ \\
\hline Sample 1 & 0.3 & 0.3046 & 98.17 & $0.0011 \pm 3.83$ \\
Sample 2 & 0.7 & 0.7003 & 99.59 & $0.0079 \pm 1.13$ \\
Sample 3 & 3.0 & 2.8981 & 103.19 & $0.0092 \pm 3.17$ \\
Sample 4 & 7.0 & 6.941 & 100.04 & $0.0057 \pm 0.82$ \\
\hline
\end{tabular}

${ }^{(a)}$ Mean average of five determinations. 
Table 3. Determination of chalcone in urine samples.

\begin{tabular}{|c|c|c|c|c|}
\hline Urine & Spiked $(\mu \mathrm{M})$ & $\operatorname{Detected}^{(a)}(\mu \mathrm{M}) \mathrm{F}$ & Recovery (\%) & $\mathrm{SD} \pm \mathrm{RSD}(\%)$ \\
\hline Sample 1 & 0.3 & 0.2946 & 101.22 & $0.0014 \pm 4.89$ \\
\hline Sample 2 & 0.7 & 0.6773 & 103.03 & $0.0180 \pm 2.65$ \\
\hline Sample 3 & 3.0 & 3.001 & 99.75 & $0.0144 \pm 0.47$ \\
\hline Sample 4 & 7.0 & 7.123 & 98.98 & $0.0757 \pm 1.07$ \\
\hline
\end{tabular}

${ }^{(a)}$ Mean average of five determinations.

\subsection{Detection of Chalcone in Urine Samples}

The applicability of the DPV to the determination of chalcone in spiked urine was investigated. The recoveries from urine were measured by spiking drug free urine with known amounts of chalcone. The urine samples were diluted 100 times with the phosphate buffer solution before analysis without further pretreatments. A quantitative determination can be carried out by adding the standard solution of chalcone into the detect system of urine sample. The calibration graph was used for the determination of spiked chalcone in urine samples. The detection results of four urine samples obtained are listed in Table 3. The recovery determined was in the range from $98.0 \%$ to $103.0 \%$ and the R.S.D. was $2.77 \%$. Thus, satisfactory recoveries of the analyte from the real samples and a good agreement between the concentration ranges studied and the real ranges encountered in the urine samples when treated with the drug make the developed method applicable in clinical analysis.

\section{Conclusion}

A glassy carbon electrode was used first time for the oxidation of chalcone in phosphate buffer solution. When the potential was made to move, chalcone produced two anodic and one cathodic peak at about $0.513 \mathrm{~V}, 1.478 \mathrm{~V}$ and $-0.689 \mathrm{~V}$ in $\mathrm{pH} 3.0$ phosphate buffer, respectively. A suitable mechanism was proposed. The peak at about 0.51 $\mathrm{V}$ was suitable for analysis and the peak current was linear to chalcone concentrations over a certain range under the selected conditions. This method can be used for voltammetric determination of selected analyte as low as 0.18 $\mu \mathrm{M}$ with good reproducibility. The proposed method offered the advantages of accuracy and time saving as well as simplicity of reagents and apparatus. In addition, the results obtained in the analysis of chalcone in spiked human plasma and urine samples demonstrated the applicability of the method for real sample analysis.

\section{Acknowledgements}

One of the authors, Keerti M. Naik, acknowledges Dr. B. E. Kumara Swamy, Department of Industrial Chemistry, Kuvempu University, Shankaraghatta, India for useful discussions.

\section{REFERENCES}

[1] C. L. Ye, J. W. Liu, D. Z. Wei, Y. H. Lu and F. Qian, "In Vitro Anti-Tumor Activity of 2, 4-Dihydroxy-6-methoxy-3, 5-Dimethylchalcone against Six Established Human Cancer Cell Lines," Pharmacological Research, Vol. 50, No. 5, 2004, pp. 505-510. doi:10.1016/j.phrs.2004.05.004

[2] O. V. Yarishkin, W. R. Hyung, P. Jae-Yong, S. Y. Min, H. Seong-Geun and H. P. Ki, "Sulfonate Chalcone as New Class Voltage-Dependent $\mathrm{K}^{+}$Channel Blocker," Bioorganic \& Medicinal Chemistry Letters, Vol. 18, No. 1, 2008, pp. 137-140. doi:10.1016/j.bmcl.2007.10.114

[3] L. Ni, C. Q. Meng and J. A. Sikorski, "Recent Advances in Therapeutic Chalcones," Expert Opinion on Therapeutic Patents, Vol. 14, No. 12, 2004, pp. 1669-1691. doi: $10.1517 / 13543776.14 .12 .1669$

[4] B. Uslu and S. A. Ozkan, "Electrochemical Characterisation of Nefazodone Hydrochloride and Voltammetric Determination of the Drug in Pharmaceuticals and Human Serum," Analytica Chimica Acta, Vol. 462, No. 1, 2002, pp. 49-57. doi:10.1016/S0003-2670(02)00280-5

[5] J. M. Kauffmann, M. P. Prete, J. C. Vire, G. J. Patriarche and Fresenius, "Voltammetry of Pharmaceuticals Using Different Types of Modified Electrodes," Fresenius" Journal of Analytical Chemistry, Vol. 321, No. 2, 1985, pp. 172-176. doi:10.1007/BF01117759

[6] F. Belal, H. Abdinic and N. Zoman, "Voltammetric Determination of Nilvadipine in Dosage Forms and Spiked Human Urine," Journal of Pharmaceutical and Biomedical Analysis, Vol. 26, No. 4, 2001, pp. 585-592. doi:10.1016/S0731-7085(01)00485-X

[7] P. Zuman, "Current Status of Polarography and Voltammetry in Analytical Chemistry," Analytical Letters, Vol. 33, No. 2, 2000, pp. 163-174. doi:10.1080/00032710008543044

[8] T. B. Demircigil, S. A. Ozkan, O. Coruh and S. Yilmaz, "Electrochemical Behaviour of Formoterol Fumarate and Its Determination in Capsules for Inhalation and Human Serum Using Differential Pulse and Square Wave Voltammetry," Electroanalysis, Vol. 14, No. 2, 2002, pp. 122 127.

doi:10.1002/1521-4109(200201)14:2<122::AID-ELAN12 2>3.0.CO;2-1

[9] S. A. Kumar, C. F. Tang and S. M. Chen, "Poly (4Amino-1-1'-azobenzene-3,4'-disulfonic Acid) Coated Electrode for Selective Detection of Dopamine from Its Interferences," Talanta, Vol. 74, No. 4, 2008, pp. 860-866. doi:10.1016/j.talanta.2007.07.015

[10] V. C. Diculescu, S. Kumbhat and A. M. O. Brett, "Electrochemical Behaviour of Isatin at a Glassy Carbon Electrode," Analytica Chimica Acta, Vol. 575, No. 2, 2006, pp. 190-197. doi:10.1016/j.aca.2006.05.091

[11] J. A. Kumar and S. Sondu, "Kinetics and Mechanism of Oxidation of Chalcones by Ti-Ichloroisocyanuric Acid

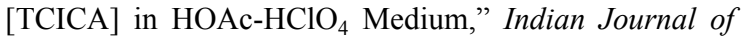
Chemistry, Vol. 46A, 2007, pp. 1792-1795.

[12] A. Shah, A. Khan, R. Qureshi, F. Ansari, M. Nazar and S. Shah, "Redox Behavior of Anticancer Chalcone on a Glassy Carbon Electrode and Evaluation of Its Interaction 
Parameters with DNA," International Journal of Molecular Sciences, Vol. 9, No. 8, 2008, pp. 1424-1434. doi:10.3390/ijms9081424

[13] G. D. Christian and W. C. Purdy, "Residual Current in Orthophosphate Medium," Journal of Electroanalytical Chemistry, Vol. 3, No. 6, 1962, pp. 363-367. doi:10.1016/0022-0728(62)80012-6

[14] B. Rezaei and S. Damiri, "Voltammetric Behavior of Multi-Walled Carbon Nanotubes Modified ElectrodeHexacyanoferrate(II) Electrocatalyst System as a Sensor for Determination of Captopril," Sensors and Actuators B: Chemical, Vol. 134, No. 1, 2008, pp. 324-331. doi:10.1016/j.snb.2008.05.004

[15] B. Eswarappa, B. S. Sherigara and B. E. K. Swamy, "Electrochemical Investigation of Benzelidene Benzyl Hydrazide and Its Derivative Shciff Bases at Glassy Carbon Electrode," Bulletin of Electrochemistry, Vol. 20, 2004, pp. 1-6.

[16] A. M. Oliveira Brett, V. Diculeseu and J. A. P. Piedade, "Electrochemical Oxidation Mechanism of Guanine and Adenine Using a Glassy Carbon Microelectrode," Bioelectrochemistry, Vol. 55, No. 1-2, 2002, pp. 61-62. doi:10.1016/S1567-5394(01)00147-5

[17] R. N. Goyal and A. Sangal, "Electrochemical Investiga-

\section{Abbreviations}

CV: Cyclic voltammetry; DPV: Differential pulse voltammetry; SWV: Square wave voltammetry; n: Number of electrons transferred; $\mathrm{I}_{\mathrm{pa}}$ : Anodic peak current; $\mathrm{D}_{0}$ : Diffusion coefficient; $\mathrm{A}_{0}$ : Surface area of the electrode; $v$ : tions of Adenosine at Solid Electrodes," Journal of Electroanalytical Chemistry, Vol. 521, No. 1-2, 2002, pp. 7280. doi:10.1016/S0022-0728(02)00645-9

[18] R. N. Goyal, A. Kumar and A. Mittal, "Oxidation Chemistry of Adenine and Hydroxyadenines at Pyrolytic Graphite Electrodes," Journal of the Chemical Society, Perkin Transactions, Vol. 2, No. 9, 1991, pp. 1369-1375.

[19] D. K. Gosser, "Cyclic Voltammetry: Simulation and Analysis of Reaction Mechansims," Vancouver Coastal Health, New York, 1993

[20] A. J. Bard and L. R. Faulkner, "Electrochemical Methods Fundamentals and Applications," 2nd Edition, Wiley, Hoboken, 2004.

[21] J. Herovsky and J. Rute, "Principles of Polarography," Academic Press, New York, 1966.

[22] E. Niranjana, R. R. Naik, B. E. K. Swamy, B. S. Sherigara and H. Jayadevappa, "Studies on Adsorption of Triton X-100 at Carbon Paste and Ceresin Wax Carbon Paste Electrodes and the Enhancement Effect in Dopamine Oxidation by Cyclic Voltammetry," International Journal of Electrochemical Science, Vol. 2, 2007, pp. 923-934.

Scan rate; $\mathrm{C}_{0}$ : Concentration; $\mathrm{T}$ : Absolute temperature; $\mathrm{R}$ :

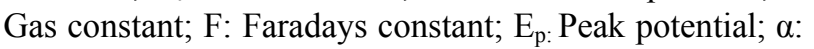
Transfer coefficient; LOD: Limit of detection; LOQ: Limit of quantification; RSD: Relative standard deviation. 